Session 2793

\title{
Engineering Curricula Change across the Foundation Coalition: How They Succeeded, What They Learned
}

\author{
Prudence Merton, Carolyn Clark, Jim Richardson, Jeffrey Froyd \\ Texas A\&M University / Texas A\&M University / University of \\ Alabama / Texas A\&M University
}

\begin{abstract}
The National Science Foundation (NSF) funded the engineering education coalitions program to profoundly change the culture of engineering education. The culture of engineering education encompasses not only the way an engineering curriculum is prepared and shared with students, but also the processes through which engineering curricula grow and improve. Therefore, the Foundation Coalition has undertaken a qualitative research project that examines processes through which coalition partners have initiated and attempted to sustain curricular change. It is important to emphasize that the focus of the study is the process of curricular change, not content of new curricula. The project is organized as series of six qualitative case studies that examine curricular change at each of the partner institutions. Data for each case study is collected through interviews of approximately twenty key faculty and administrators as well as review of relevant documentation. Each case study identifies critical events and salient issues involved in that process, as well as valuable lessons each institution learned from their experience. To date, interviews have been conducted at four the six institutions, but the present report will be based on data from the first three institutions at which interviews have been completed.
\end{abstract}

To date, several themes have emerged from analysis.

- Each of the institutions initiated curricular improvement by developing a pilot program and offering it to a relatively small number of students. Initiating improvement via pilot programs is well-accepted developmental strategy for engineering artificial systems, but it offers benefits and presents challenges in an educational environment. Expanding from a pilot curriculum to a curriculum for an entire college of engineering also presents challenges in terms of faculty development and facility costs. Pilots should be planned both to study the proposed improvements as well as to support eventual adoption across the entire college.

- Building support for curricular improvement within and beyond the College of Engineering required significantly more design and effort than anticipated by the change leaders. Based on the interviews, building support requires widespread communication, selection of influential faculty, political strategizing and assessment data. Communication plans require substantial up-front investment in addition to the efforts required to implement the plans.

"Proceedings of the 2001 American Society for Engineering Education Annual Conference \& Exposition Copyright (C) 2001, American Society for Engineering Education” 
- The emphasis on research in most institutions presents significant obstacles for those who want to play an active role in curricular improvement.

Our study demonstrates that effecting major change in engineering curricula is a complex process but one that can succeed with careful planning and sustained effort. It is our hope that the experience of the partners of the Foundation Coalition will be helpful to other engineering programs as they plan for curricular change.

\section{Introduction}

The National Science Foundation (NSF) initiated the Engineering Education Coalitions program in 1990 to stimulate the creation of comprehensive, systemic models for reform of undergraduate engineering education. To accomplish this reform the Coalitions are developing tested alternative education tools, curricula, and delivery systems. By applying these tools, they also hope to increase the successful participation of underrepresented groups in engineering education and to improve linkages to K-14 educational institutions. Through cross-coalition collaboration they will develop significant intellectual exchange and resource links among undergraduate engineering programs. NSF has funded eight coalitions. The Foundation Coalition (FC), which was first funded in 1993, currently has six participating institutions--Rose Hulman Institute of Technology (RHIT), Texas A\&M University (TAMU), University of Alabama (UA), University of Wisconsin-Madison (UW), Arizona State University (ASU), and University of Massachusetts-Dartmouth (UMD). Together they are developing and implementing innovative engineering curricula based on four "thrusts": integration of conceptual concepts across courses; active and cooperative learning; the use of technology in the classroom; and on-going assessment and evaluation.

Implementing significant curricular change in higher education is an enormous challenge, both in scope and complexity. In this study we are examining how each of the six FC partner institutions designed and implemented a new curriculum on their campus. Our focus is on the process they went through, not on the content of the curriculum itself. To understand this process we are conducting a series of qualitative case studies at the six FC partner institutions. Data for these studies are being collected through individual interviews with approximately 20 key faculty and administrators on each partner campus, as well as through review of related documents. Each case study identifies critical events and salient issues involved in that process, as well as the lessons faculty at each institution learned from their experience.

Midway through this study we are finding several issues in the stories of curricular change that all the institutions have struggled with and learned from. Here we identify three of those issues and discuss how three of the FC institutions: RHIT, TAMU, and UA have dealt with them and what lessons they learned.

\section{ISSUE 1: Transition: Pilot Curriculum to Mainstream Curriculum}

Although it seems logical to design a new curriculum and then pilot it with a small

"Proceedings of the 2001 American Society for Engineering Education Annual Conference \& Exposition Copyright (C) 2001, American Society for Engineering Education” 
number of students, starting with a pilot program may create significant obstacles when moving toward implementation for the entire college. All three schools piloted their new curriculum with a small number of students for several years, allowing them to make improvements as they went along. However, the pilot curricula that worked for a limited number of students and faculty might not work on a larger scale, i.e., more students and more faculty, and would not work for students with different needs, e.g., students who are not calculus ready, students who have received advanced placement for one or more courses in science and mathematics, and transfer students. Scaling up to larger numbers of students required more classrooms equipped with computers and more faculty members trained in the new pedagogy. Diverse student needs must also be accommodated when a curriculum moves to the mainstream. Ways must be found to accommodate a much broader set of students than those who participated in the pilot curricula, for example, entering students who are calculus-ready as well as those who are not; transfer students; and students who fail a course and must retake that course while moving forward with the other sequenced courses. Alternative curricular paths must be constructed to accommodate students who enter with different backgrounds.

Furthermore, managing different curricular paths and clustering students both require flexibility and creativity, and a lot of work with the registrar.

It became clear to faculty and administrators at these three institutions that some kind of curricular accommodation had to be made when moving from a small group of students to a large group. The level of curricular integration in the pilot curricula could not be maintained. Making major changes in the pilot curricula was a very difficult experience for those faculty members who had developed pilot curricula only to see some of their ideas being "watered down" in the transition to mainstream. However, those leading the change process consistently argued that the final result was still a significant improvement over the original curriculum.

Further, once the modified pilot curricula were adopted across the entire college, issues of ownership had to be settled; the new curriculum was no longer the responsibility of the developers. For first-year freshman curricula control was usually given to the dean's office, most often administered by a freshman year coordinator. This made sense because there is only one engineering course each semester and the rest are courses in other colleges. The situation was different for the sophomore curriculum, since it involves primarily engineering courses (usually four each semester). At TAMU and RHIT each of the core courses was given to appropriate departments, with the departments having control over the content. This decision increased the support for the courses within these departments, but it also meant that the courses could evolve differently from the intent of the original developers.

Each of the pilot curricula stressed increased access to powerful computer software and hardware by the students. Making sure every student has access to a computer in the classroom meant classrooms had to be built and equipped with computers. Equipping one or two classrooms could be accomplished with funds used to match the NSF funds or in special cases with NSF funds. However, expanding the infrastructure to support instruction across the entire college was a major commitment. In addition, it continues to

"Proceedings of the 2001 American Society for Engineering Education Annual Conference \& Exposition Copyright (C) 2001, American Society for Engineering Education” 
be necessary to update the equipment in the new classrooms on a regular basis. Each of the institutions has developed innovative ways to meet the fiscal challenges.

In any curricular change process, it is not just the curricular content that changes. With the FC emphasis on using other teaching innovations like cooperative and active learning, employing technology in the classroom, and the use of student teams, faculty members were required to change as well. For many, changes from the traditional teaching routine of lecture/lab to more intense and interactive teaching methods were difficult. Not only did they need to become familiar with new content but with a new delivery methods as well. All three institutions discovered that it was necessary to establish an on-going program of faculty development. Participation in these programs was voluntary, a feature popular with faculty but this also meant that not all faculty members who taught these courses had been exposed to the new pedagogy.

\section{Issue 2: Building Support within and beyond the Impacted College or Departments}

Gaining support for curricular change within and beyond the impacted college or departments is critical, but what are the best ways to do it?

Designing a new curriculum is an exercise in futility unless implementation is supported $t$ at all levels of the institution. Building the required level of support throughout the organization is a complex and challenging issue. The three institutions we've looked at so far have had mixed success in dealing with it. All, however, have learned useful lessons from their experiences.

Support must come from multiple constituencies. Engineering faculty as well as department heads and deans must see the value of curricular change and be committed to the principles of the new curriculum. Students have to see the new program as valuable. Department heads and deans of other colleges providing courses for engineering students, e.g., physics, math, chemistry, English, need to have incentives for participation in the curriculum. The university community, especially provosts and presidents, must see benefits of a new engineering curriculum for the entire university. And industry should believe that their future employees will be better prepared to meet the challenges that employers will confront.

The three institutions found that a number of strategies for gaining support are effective across most or all of these constituency groups. Probably the most basic is widespread and on-going communication. The more public the curricular change effort is, the more likely others are to support it. Effective communication requires sustained intention and a level of effort that is difficult to maintain while trying to also make substantive curricular changes. All of the three institutions recognized the importance of this more in hindsight. They also learned that communication needs to be two-way, not just imparting information but also seeking feedback. If people feel they are being heard, then their support is more likely.

It is also important to choose influential people to be involved in the change process. At

"Proceedings of the 2001 American Society for Engineering Education Annual Conference \& Exposition Copyright (C) 2001, American Society for Engineering Education” 
all three institutions that meant selecting faculty for leadership in the new program who were not only good teachers but also well regarded by their peers. TAMU included a few notable researchers to give greater legitimacy to the new curriculum. They also sought out the support of high profile scholars (locally termed "bell cows") in the belief that they would have more influence across the college. In working with colleges outside engineering, they learned that they needed to carefully identify the influential faculty in the relevant departments. In one case, the early involvement of willing faculty member who did not command the respect of colleagues in a non-engineering department meant that the department did not fully support the pilot curriculum and has not supported mainstream implementation to date. In this case it was a mistake from which they have not yet recovered.

All three institutions learned the importance of political strategizing, often from their mistakes. At UA, for example, there was some support from the dean and the provost, but for the most part it was a bottom-up effort, being pushed by the faculty who developed the curriculum. This was not an effective strategy. RHIT and TAMU learned to gain the support of people in leadership at all levels. All agree that the earlier this is accomplished, the better. Building support also implies soliciting input from these people and being willing to incorporate it in some way into the curricular design.

TAMU adopted an explicit strategy to build support by identifying and responding to areas of resistance directly, instead of only advocating for the innovation. They tried to listen to complaints about the curriculum, sit down with influential critics and take suggestions from them. ${ }^{1}$ Responding to resistance required flexibility and the willingness to make adjustments while striving to adhere to the underlying principles of the innovation. However, flexibility by associate deans and department heads was often viewed as compromise for the sake of mainstream adoption by many of the faculty members who developed the pilot curriculum.

Finally, everyone discovered that assessment data are necessary, though not sufficient, to win widespread support for the new curriculum. The three institutions were not equally successful in doing this, but those who made assessment a priority early on had an easier time getting the curriculum adopted than those who had insufficient assessment data.

The three institutions learned that curricular change really means effecting change within a highly complex system. Gaining the necessary support meant understanding that system and addressing the key constituencies successfully.

\section{Issue 3: Faculty Rewards for Educational Innovations}

When faculty members engage in curricular reform it is an intense and time-consuming activity. What reward do they get for all this work and what part does it play in tenure and promotion decisions?

The question of faculty reward for innovation in higher education is problematic, but it is an issue that is context-dependent. At Research I and II institutions like TAMU and UA,

\footnotetext{
"Proceedings of the 2001 American Society for Engineering Education Annual Conference \& Exposition Copyright C 2001, American Society for Engineering Education"
} 
rewarding excellence in teaching is a distant second to research. At nontraditional institutions like RHIT, teaching is the central mission. Pay-off for faculty members who develop new curricula is therefore different in each context.

At traditional research institutions there is an inherent risk for faculty in doing curriculum development. Because it takes time away from their research agenda, it means that they will be in a weakened position when they are considered for promotion or tenure.

Additionally, by being associated so strongly with teaching, they risk having diminished prestige among their colleagues. Because of this climate, at both UA and TAMU untenured faculty were usually not encouraged to get involved in the curriculum development process or in teaching the new courses. Their department heads typically protected the few who did teach by providing release time. Things were less clear for associate professors. At both institutions no one who had taken a leadership role in the FC program has yet been promoted to full professor, though one person is up for promotion this year. It is not uncommon for work in curriculum development to be considered as service in these institutions, which may count even less than teaching, so concerns about promotion are well founded.

Those in leadership at UA and TAMU try to resolve the tension between working for curricular development and the reward system by arguing that faculty who do this need to be publishing in peer-reviewed engineering education journals. Essentially they believe that this work can be rewarded if it is fitted into the traditional models of research. This argument isn't entirely persuasive to many of the junior faculty involved in this effort. Some of them say that they are resigned to being an associate professor and find their reward in the teaching itself. Others argue that Research I and II institutions need to develop a new model that legitimates innovative work done in teaching, though they are pessimistic that this will ever happen.

At RHIT, an institution where teaching is highly valued, the issues change. Here the tensions are around what constitutes good teaching. Those involved in the new curriculum have to defend the pedagogy that is promoted in that curriculum. Colleagues who teach in traditional ways may or may not believe that the new pedagogy has merit.

One dean at the three institutions noted that we need to think of reward more broadly than promotion and tenure-universities need to find more ways to show appreciation for the work of faculty in designing and implementing new curricula. This is a human issue, not only a matter of prestige. Their college gave a dinner for all those involved in the new curriculum to thank them for their efforts. It seems like a small thing, but in the competitive culture of higher education it is unusual to simply say 'Thank you' for a job well done, yet it can make a real difference in faculty morale.

The issue of rewards for teaching remains problematic since it challenges the fundamental culture of academia. So far we are not seeing any evidence that that culture is amenable to significant change in this regard.

"Proceedings of the 2001 American Society for Engineering Education Annual Conference \& Exposition Copyright C 2001, American Society for Engineering Education" 


\section{Conclusion}

Large-scale curricular changes in higher education are complex and challenging processes. The three partner FC institutions that we have studied so far have had uneven success in attaining this goal, but their experience has taught them many helpful lessons about the process. Hopefully, the following lessons will be helpful to other institutions undertaking curricular reform.

- When implementing a pilot curriculum, faculty members should thoughtfully consider what the pilot curriculum will be designed to demonstrate. Design of the pilot curriculum and design of the assessment and evaluation plan should be done simultaneously. Efforts should be made to find ways in which all of the college or department faculty can be involved in the design, implementation, assessment and evaluation of the pilot curriculum.

- Effective communication, both one-way and two-way, to inform and involve faculty members requires an unexpected level of thought and effort.

- The issue of rewards for teaching remains problematic since it challenges the fundamental culture of academia. So far we are not seeing any evidence that that culture is amenable to significant change in this regard.

Bibliography

1. Fournier-Bonilla, S., Watson, K., Malavé, C., Froyd, J. "Managing Curricula Change in Engineering at Texas A\&M University," International Journal of Engineering Education, to appear

\footnotetext{
PRUDENCE MERTON

Prudence Merton is a qualitative researcher and adult educator with Peace Corps training experience. Ms. Merton has a Masters of Science degree in Horticulture from Texas A\&M University and is currently working on her dissertation in Adult Education that she plans to complete by December 2001.
}

\section{CAROLYN CLARK}

M. Carolyn Clark is an associate professor of adult education at Texas A\&M University. She received her doctorate in adult education from the University of Georgia in 1991. Her research interests include learning and identity development, transformational learning, and narrative as a mode of learning and development. She is a qualitative researcher, and she teaches and writes on qualitative methodology.

\section{JEFFREY FROYD}

Jeffrey Froyd is a Visiting Professor of Electrical Engineering at Texas A\&M University and currently serves as the Project Director NSF Foundation Coalition. He earned a B.S. in Mathematics from RoseHulman Institute of Technology and M.S. and Ph.D. degrees in Electrical Engineering from the University of Minnesota. His interests include control systems design, VLSI design, and engineering education.

"Proceedings of the 2001 American Society for Engineering Education Annual Conference \& Exposition Copyright (C) 2001, American Society for Engineering Education” 